\title{
VER EM FRANCÊS ACADIANO E PORTUGUÊS BRASILEIRO: CODIFICAÇÃO DE IMPERATIVO E SALIÊNCIA TEXTUAL
}

\author{
Catherine LÉGER* \\ Marcus LUNGUINHO ${ }^{* *}$ \\ Patrícia RODRIGUES ${ }^{* * *}$
}

- RESUMO: Este artigo discute construções do português brasileiro (PB) e da fala informal do francês acadiano (FA) nas quais formas equivalentes à do verbo 'ver' aparecem em enunciados imperativos contendo um segundo verbo. Nessas construções, 'ver' enfatiza a injunção expressa por esse segundo verbo. A construção do PB apresenta também uma leitura adicional, na qual a forma $v \hat{e}_{\text {IMPRRAIvo }}$ tem o significado de 'verificar'. O artigo propõe que as construções do PB podem ser associadas a duas estruturas distintas. As construções com o significado de 'verificar' são tratadas como estruturas bioracionais nas quais o verbo 'ver' seleciona um CP nucleado pelo complementador se. Com relação à análise do significado de ordem enfática associado às construções do PB e do FA, adota-se as propostas de Speas e Tenny (2003) e de Hill (2007, 2014), segundo as quais a pragmática conversacional é codificada na sintaxe com uma estrutura predicativa (uma projeção associada ao Speech Act 'Ato de Fala'- SAP) acima de CP. Com base nessas propostas, analisam-se as construções de ordem enfática do PB e do FA como estruturas mono-oracionais, em que vê e voir são marcadores pragmáticos injuntivos inseridos diretamente no núcleo SA para codificar uma relação pragmática.

- PALAVRAS-CHAVE: marcador pragmático; verbos de percepção; línguas românicas; gramaticalização; dessemantização.

\section{Introdução}

Sabe-se que verbos de percepção, tais como ver, podem selecionar uma vasta gama de complementos finitos e não finitos que estão associados a diferentes tipos de categorias semânticas (eventos, proposições, etc.) e que esses verbos apresentam

\footnotetext{
University of Victoria (UVIC). Faculty of Humanities. Victoria - BC - Canadá. Department of French. cleger@uvic. ca. ORCID: 0000-0003-2039-1208.

** Universidade de Brasília (UnB). Instituto de Letras. Brasília - DF - Brasil. Departamento de Linguística, Português e Línguas Clássicas. marcuslunguinho@gmail.com. ORCID: 0000-0002-2871-0739.

*** Universidade Federal do Paraná (UFPR). Setor de Ciências Humanas. Curitiba - PR - Brasil. Departamento de Literatura e Linguística. rodriguespatriciaa@gmail.com. ORCID: 0000-0002-3534-284X.
} 
diferentes leituras (direta, indireta, imaginativa) dependendo do tipo de complemento com que ocorrem. Por exemplo, enquanto a presença de uma sentença finita induz a chamada interpretação "indireta" do verbo de percepção (1), a presença de um complemento não finito induz uma leitura "direta" (2)1 (AKMAJIAN, 1977; GUASTI, 1993; LABELLE, 1996; BOIVIN, 1998; FELSER, 1999; MILLER; LOWREY, 2003, entre outros). Esses verbos também permitem uma leitura imaginativa (3), isto é, uma percepção situada na imaginação do experienciador (OLSSON, 1976; BOIVIN, 1998; WILLEMS; DEFRANCQ, 2000; RODRIGUES, 2006).

(1) a. J'ai vu (à son allure) que Jean était ivre. (leitura indireta)

b. Eu vi (pelo seu jeito) que Jean estava bêbado.

(2) a. J'ai vu (*à son allure) Jean boire/buvant. (leitura direta)

b. Eu vi (*pelo seu jeito) Jean beber/bebendo.

(3) a. Je vois Jean boire. (leitura imaginativa)

b. Eu vejo Jean bebendo.

No entanto, em algumas línguas românicas, as contrapartes de ver têm outros significados e usos que ainda não foram amplamente estudados. Por exemplo, na fala informal do francês acadiano (FA) e em português brasileiro (PB), formas equivalentes a ver podem aparecer em enunciados injuntivos em que elas não expressam nem leituras diretas, nem indiretas, nem imaginativas. Nesses enunciados, elas parecem enfatizar (em algumas leituras) o comando expresso pelo verbo principal, como em (4) ou (5).

(4) Écoute voir!

escutar.2sg.IMP ver.INF ${ }^{2}$

'Ouça!'

(5) Vê se me escuta! ${ }^{3}$

Em FA, como em outras variedades do francês, o infinitivo voir (literalmente: 'ver') pode coocorrer com verbos imperativos, como em (4); entretanto, nesse tipo de enunciado, voir não apresenta as propriedades morfossintáticas e semânticas do verbo de percepção do qual ele parece ser derivado (ver a seção "voir no Francês Acadiano"). Argumentamos que esse uso de voir tem uma função enfática: ele reforça o valor

1 Os rótulos direto e indireto estão relacionados ao contato do experienciador com o evento percebido. A percepção indireta é geralmente resultado de uma atividade inferencial baseada em evidência relacionada à situação descrita (em (1), a forma como Jean estava balbuciando, por exemplo). Percepção direta, por outro lado, não pode se basear na percepção dessa evidência (2).

2 As seguintes abreviações serão doravante utilizadas neste artigo: $2=2^{\mathrm{a}}$ pessoa; $3=3^{\mathrm{a}}$ pessoa; EXPL=expletivo; $\mathrm{FUT}=$ futuro; IMP=imperativo; INF=infinitivo; $\mathrm{PTCP}=$ particípio; $\mathrm{PRS}=$ presente; $\mathrm{IND}=$ =modo indicativo; $\mathrm{SG}=$ singular; $\mathrm{PL}=$ plural; $\mathrm{SBJV}=$ modo subjuntivo.

3 A forma escuta está no presente do indicativo, segunda pessoa singular; não é a forma do imperativo verdadeiro do verbo escutar. A sentença em (i), na qual o verbo está no plural, confirma essa análise:

(i) Vê se vocês me escutam desta vez! 
imperativo ao anunciar para o ouvinte que o contexto linguístico ou extralinguístico é tal que requer que ele execute a ação denotada pelo imperativo.

A construção do PB em (5) pode ter a mesma leitura que aquela em (4) em FA: ela pode ser entendida como uma ordem enfática que leva em consideração informação saliente no contexto linguístico ou extralinguístico. Contudo, essa construção pode ter outra interpretação, na qual ver significa 'verificar'. Assim, (5) é ambígua e poderia ser enunciada em dois contextos diferentes, como, por exemplo:

(i) em um contexto em que o falante diga "você nunca me escuta, você nunca presta atenção no que eu falo, mas, no final das contas, eu sempre estou certo" (uma ordem enfática);

(ii) em um contexto em que o falante diga "a ligação [do telefone] está muito ruim; vamos testar para ver se você me ouve." Dessa forma, ambas as leituras expressam uma ordem, mas a primeira veicula uma ordem enfática, que requer que o ouvinte execute a ação denotada pelo segundo verbo na sentença, ao passo que a segunda veicula uma ordem ou um pedido que requer uma ação de verificação; o significado de verificação é expresso pelo verbo ver.

O objetivo principal deste artigo é examinar as propriedades das construções em FA e em PB com leitura de ordem enfática a partir da esfera da pragmática conversacional. Para isso, será primeiramente necessário diferenciar os dois significados da construção em PB apresentados em (5). Propomos que a construção em PB em (5) pode estar associada a duas estruturas diferentes. A construção com o significado de 'verificar' seria uma estrutura bioracional em que o verbo ver seleciona um CP nucleado pelo complementizador se, como em (6):

(6) $\left[_{\mathrm{vP}} \mathrm{DP}\left[_{\mathrm{v}}, \mathrm{v}\left[_{\mathrm{VP}} \operatorname{ver}\left[_{\mathrm{CP}} \mathrm{se}\left[_{\mathrm{TP}} \cdots\right.\right.\right.\right.\right.$

Quanto à análise do significado de ordem enfática associado a (5) e à construção em FA em (4), seguiremos as propostas de Speas e Tenny (2003) e Hill (2007, 2014). De acordo com essas autoras, a pragmática conversacional estaria codificada na sintaxe na forma de uma estrutura predicativa (sintagma Speech Act 'Ato de Fala' SAP), acima de CP. Adotando essas ideias, analisaremos as construção de ordem enfática nessas duas línguas como estruturas mono-oracionais, nas quais vê e voir são marcadores pragmáticos injuntivos que codificam endereçamento direto (direct address), e defenderemos que esses marcadores são inseridos diretamente (externally merged) no núcleo de SA para codificar uma relação pragmática.

Este artigo está organizado da seguinte forma. A próxima seção apresenta algumas noções que servirão de base para o restante do trabalho. A terceira seção discute dados do FA, examinando as propriedades morfossintáticas e semânticas de voir, assim como sua distribuição. A quarta seção examina dados do PB e discute as diferenças entre as duas leituras da construção em (5) ${ }^{4}$. Em seguida, na quinta seção, desenvolvemos

4 Essa discussão foi baseada em Rodrigues e Lunguinho (2017). 
uma comparação entre as construções do FA e do PB. A sexta seção expõe o quadro teórico no qual a análise está baseada, e na sétima seção apresentamos nossa proposta. A oitava seção traz nossas considerações finais.

\section{Noções teóricas preliminares}

Nesta seção, apresentamos brevemente alguns conceitos-chave que usaremos para caracterizar os enunciados do FA e do PB examinados neste artigo. Esses enunciados podem ser compreendidos como parte do conjunto de atos de fala diretivos ${ }^{5}$, cujo propósito ilocucionário é "uma tentativa de fazer com que o ouvinte faça alguma coisa" (SEARLE, 1975, p. 158) ou aja de determinada forma. Construções diretivas envolvem principalmente ordens e comandos, mas diretivas mais moderadas podem incluir pedidos, instruções ou sugestões.

Em geral, é o imperativo que é utilizado em atos de fala diretivos, mas outros tipos de sentença também podem cumprir essa função. Vale ainda notar que sentenças imperativas podem ser não diretivas (KISSINE, 2013; JARY; KISSINE, 2016). Dessa forma, mesmo estando no modo indicativo, iremos analisar as sentenças em PB que expressam ordem enfática como atos de fala diretivos.

Ao discutir o significado de imperativos, Aikhenvald (2010, p. 203) argumenta que significados diretivos "se correlacionam com uma propriedade geral da força ou do grau de um comando" e que a "ênfase nos imperativos está frequentemente ligada à força do comando - quanto mais insistente o comandante, mais ênfase ele colocará no comando". A autora explica que um imperativo por si só pode veicular uma ordem neutra. Entretanto, esta ordem pode ser comunicada com mais força, isto é, a natureza peremptória do comando pode ser intensificada; nesse caso, "espera-se que imperativos sejam mais formalmente marcados que imperativos neutros" (AIKHENVALD, 2010, p. 204). Para ilustrar essa propriedade, Aikhenvald traz um exemplo de Haro, uma língua omótica da Etiópia, em que um enunciado marcado pelo enfatizador -tte seguindo o imperativo expressa um comando mais forte que o imperativo neutro.

Portanto, ainda que a noção de ênfase seja intuitiva, nós assumimos que uma ordem enfática é um recurso que o falante emprega para mostrar ao ouvinte que o contexto é tal que ele (ouvinte) deve executar a ordem dada. Algumas marcações gramaticais de ênfase disponíveis nas línguas seriam, por exemplo, prosódia característica, presença/ausência do sujeito, ou o uso de marcadores ${ }^{6}$. Nós assumimos que as formas pragmaticalizadas em FA e em PB discutidas neste artigo são parte da gama de recursos que podem ser utilizados para marcar ênfase em atos de fala diretivos. Como nosso objetivo principal é discutir essa leitura enfática em contraste com um uso mais neutro de imperativos,

\footnotetext{
5 Para uma caracterização de atos de fala, ver, por exemplo, Searle (1975).

6 Para uma discussão extensa acerca da marcação gramatical da força de comandos, ver Ainkhenvald (2010, seção 6.3).
} 
nós não iremos diferenciar, ao falar sobre esse uso mais neutro, ordens ou comandos de pedidos ou sugestões, e usaremos esses termos sem distinção.

Quanto ao conceito de pragmaticalização, seguindo Dostie (2004, 2009), entendemos que seja um processo similar à gramaticalização, mas cujo resultado carrega uma função pragmática ao invés de uma mais gramatical. Deve ser observado que o termo gramaticalização é frequentemente utilizado na literatura para se referir à pragmaticalização. A gramaticalização é um processo de mudança linguística pelo qual itens lexicais se tornam itens gramaticais, e itens gramaticais conquistam um estatuto ainda mais gramaticalizado (HOPPER; TRAUGOTT, 2003; ROBERTS; ROUSSOU, 2003; HEINE; NARROG, 2012, entre outros). Heine e Narrog (2012) propõem um conjunto de quatro parâmetros a serem utilizados para identificar e descrever casos de gramaticalização: extensão, dessemantização, descategorização e erosão. O parâmetro de extensão se refere à emergência de novos significados a partir do uso das expressões linguísticas em novos contextos; o parâmetro de dessemantização, também conhecido como redução semântica (bleaching), refere-se à perda de conteúdo semântico; o parâmetro de descategorização diz respeito à perda de propriedades morfossintáticas; e erosão se refere à perda de substância fonética.

Argumentaremos que os enunciados em FA e PB que veiculam uma ordem enfática envolvem um marcador pragmático - respectivamente voir e vê - que passou por um processo de pragmaticalização iniciado a partir das formas dos verbos lexicais (voir e ver), que tiveram seu uso estendido para novos contextos, com a perda de conteúdo semântico e de propriedades morfossintáticas. Consequentemente, nossa visão é que esse processo é diacrônico; no entanto, uma explicação para o percurso de mudança semântica de um significado lexical para um pragmático desses marcadores está além dos objetivos desse trabalho. Além disso, a existência ou não de uma relação semântica perceptível entre o verbo lexical e o marcador pragmático não interfere na nossa descrição dos dados ${ }^{7}$.

\section{Voir no Francês Acadiano}

Nesta seção, esboçaremos uma descrição de voir em francês acadiano como utilizado em enunciados imperativos de fala (informal) espontânea. Como ilustrado em (7), voir, mais frequentemente pronunciado [we:r] nesse dialeto, pode ser utilizado em construções imperativas tanto afirmativas quanto negativas.

Para uma visão geral da discussão acerca da polifuncionalidade de marcadores discursivos e da relação entre seus significados como um caso de homonímia ou polissemia, ver Fischer (2006). 
(7) a. Arrête voir tes gestes! parar.2sG.IMP ver.INF teus gestos 'Vê se para com teus absurdos!'

b. Casse-toi voir pas la tête avec ça! quebrar.2sG.IMP-você ver.INF não a cabeça com isto 'Vê se não se preocupa com isto!'

Essas construções são encontradas em diferentes áreas das províncias do Atlântico do Canadá: Nova Escócia (BOUDREAU, 1988; HENNEMAN; NEUMANNHOLZCHUH, 2014), New Brunswick (POIRIER, 1993; WIESMATH, 2006) e Terra Nova e Labrador (BRASSEUR, 2001). Elas também são utilizadas na Louisiana (DAIGLE, 1984; PAPEN; ROTTET, 1997; PARR, 1940; VALDMAN et al., 2010).

Com relação às suas propriedades morfológicas, nesses exemplos voir não apresenta o comportamento típico de verbos em geral. De fato, em enunciados imperativos, voir é invariável na forma; ele não pode ser flexionado (8a), em contraste com o verbo de percepção visual com a mesma forma, que pode carregar todos os tipos de flexão de tempo, modo e pessoa (8b).

(8) a. Écoute voir $/ *^{\text {vois }} / *^{*}$ verras $/{ }^{*}$ voies une minute! escutar.2SG.IMP ver.INF/*ver.2sG.PRS.IND/*ver.2sG.FUT/*ver.2sG.SBJV um minuto

'Vê se escuta um minuto!'

b. Tu vois/verras/as vu.

tu ver.PRES.IND/ver.FUT/tem ver.PTCP

'Você vê/verá/viu'

As restrições distribucionais de voir em francês acadiano mostram que esse item não tem flexibilidade sintática, o que os aproxima dos clíticos: ele quase sempre tem que seguir o verbo imperativo. Sintagmas nominais, sejam complementos (9) ou adjuntos (10), não podem ser inseridos entre o verbo conjugado no imperativo e voir.

(9) a. Mange voir ta pomme!/\#Mange ta pomme voir! ${ }^{8}$ comer.2SG.IMP ver.INF tua maçã/\#comer.2SG.IMP tua maçã ver.INF 'Vê se come tua maçã!'/‘\#Come tua maçã pra ver (o que vai acontecer)!'

b. Pense voir à ta mère!/\#Pense à ta mère voir! pensar.2SG.IMP ver.INF em tua mãe/\#pensar.2sG.IMP em tua mãe ver.INF 'Vê se pensa na tua mãe!'‘„\#Pensa na tua mãe pra ver (o que vai acontecer)!’

\footnotetext{
O símbolo \# indica que o enunciado é bem formado, mas não tem a leitura pretendida. Os enunciados precedidos por \# ao longo do artigo são utilizados para desafiar alguém a fazer alguma coisa. Nesses casos, voir é utilizado para expressar uma quase ameaça, e mantém o significado do verbo de percepção visual. Esses enunciados parecem ser utilizados elipticamente, como em Goûte ça (pour) voir (ce qui se passera)! 'Prove isso (pra) ver (o que vai acontecer)!'.
} 
(10) a. Téléphone voir demain!/\#Téléphone demain voir! telefonar.2sG.IMP ver.INF amanhã/\#telefonar.2sG.IMP amanhã ver.INF 'Vê se telefona amanhã!'/\#Telefona amanhã pra ver (o que vai acontecer)!'

b. Marche voir plus vite!/\#Marche plus vite voir! andar.2SG.IMP ver.INF mais rápido/\#andar.2SG.IMP mais rápido ver.INF 'Vês se anda mais rápido!'/“\#Anda mais rápido pra ver (o que vai acontecer)!'

Além disso, o elemento de negação pas não pode intervir entre voir e o verbo, como ilustrado em (11).

(11) a. Casse-toi voir pas la tête avec ça!/*Casse-toi pas voir la tête avec ça! quebrar.2SG.IMP-você ver.INF não a cabeça com isto/* quebrar.2sG.IMP-você não ver.INF a cabeça com isto

'Vê se não se preocupa com isto!'

b. Chut! Parle voir pas!/\#Chut! Parle pas voir!

shh falar.2sG.IMP ver.INF não/\#shh falar.2sG.IMP não ver.INF

'Shh! Vê se não fala!'/\#Shh! Não fala pra ver o que vai acontecer.'

Parece que apenas alguns pronomes, isto é, clíticos, podem ser inseridos entre o imperativo e voir.

(12) a. Regarde-les voir, mes dessins!

olhar.2sG.IMP-os ver.INF, meus desenhos

'Vê se olha os meus desenhos!'

b. Mange-la voir, ta pomme!

comer.2sG.IMP-a ver.INF, tua maçã

'Vê se come a tua maçã!'

c. Brosse-toi-les voir, les dents!

escovar.2sG.IMP-você-os ver.INF, os dentes

'Vê se escova os dentes'

Os dados em (12) podem ser facilmente explicados pelo fato de que uma marca registrada dos clíticos é sua completa falta de autonomia, ou, ao menos, sua reduzida autonomia; por isso, eles precisam aparecer junto ao verbo. Como pode ser depreendido dos dados discutidos acima, o escopo de voir é muito estreito: ele é limitado ao verbo imperativo.

No que concerne as propriedades semânticas dessas estruturas, como mostrado em (13), em construções imperativas, voir pode coocorrer com um verbo de percepção (por exemplo, um verbo de percepção visual ou auditivo), o que mostra que o uso dessa forma é acompanhado da perda das características associadas à forma original 
de verbo de percepção. Em outras palavras, nesses contextos, voir é caracterizado pela dessemantização.

\section{(13) Écoute voir une minute! escutar.2SG.IMP ver.INF um minuto 'Vê se escuta um minuto!'}

Ainda, voir pode ser omitido nesses enunciados (14), o que sugere que ele não acrescenta conteúdo semântico no nível da sentença (ou apenas muito pouco); ao invés disso, sua função se situa no nível discursivo; em outras palavras, ele tem função pragmática.

\section{(14) Écoute (voir) une minute!}

Os exemplos em (15) mostram ainda que voir, em contextos imperativos, não se comporta como um verbo pleno; ele não pode ter argumentos, em contraste com o verbo de percepção visual original, que pode selecionar diferentes tipos de complementos (por exemplo, sintagmas nominais e sentenças subordinadas no indicativo).

(15) a. Imagine (voir) l'oiseau! imaginar.2SG.IMP (ver.INF) o pássaro 'Imagine o pássaro!'

b. Imagine (voir) que Marie est arrivée! imagine-2SG.IMP (ver.INF) que Marie é chegada 'Imagine que Marie chegou!'

c. Il voit l'oiseau. ele ver.3SG.PRES.IND o pássaro 'Ele está vendo o pássaro'

d. Il voit que Marie est arrivée. he ver.3SG.PRES.IND que Marie é chegada 'Ele está vendo que Marie chegou.'

Em (15a) e (15b), voir não seleciona o sintagma nominal, nem o complemento no indicativo, que são argumentos do verbo conjugado imagine. $\mathrm{O}$ fato de que voir não é obrigatório nesses enunciados fornece evidência adicional para essa afirmação. Entretanto, voir, em seu uso como verbo de percepção, aceita diferentes tipos de complementos, como ilustrado em (15c) e (15d). Se nossa hipótese for de que voir, em contextos imperativos, é derivado do verbo de percepção, então somos obrigados a concluir que ele perdeu sua estrutura argumental.

Como mostrado nos enunciados imperativos discutidos acima, voir não apresenta as propriedades morfossintáticas e semânticas/pragmáticas do verbo de percepção do qual parece ter sido derivado. No que se refere à pragmática dessas construções, argumenta-se 
que esse uso de voir tem uma função enfática: ele reforça o valor imperativo ao afirmar para o ouvinte que o contexto (linguístico ou extralinguístico) é tal que requer que ele (ouvinte) execute a ação denotada pelo imperativo. Por exemplo, em (16), voir pode ser ligado a um antecedente linguístico ou extralinguístico.

\section{(16) Ferme voir la porte! \\ fechar.2SG.IMP ver.INF a porta \\ 'Vê se fecha a porta!'}

Como exemplo de um caso em que voir pode ser associado a um antecedente linguístico, temos (17). Imaginemos uma situação em que um casal está chegando em casa depois de ir ao mercado. Nesse exemplo, um pedido havia sido previamente formulado no discurso pelo falante, mas foi ignorado pelo ouvinte. $\mathrm{O}$ uso do imperativo com voir permite ao falante sinalizar ao ouvinte que ele deve se basear no contexto que deveria ser saliente para os dois, já que o enunciado acabou de ser pronunciado -, e permite também ao falante insistir em seu pedido.

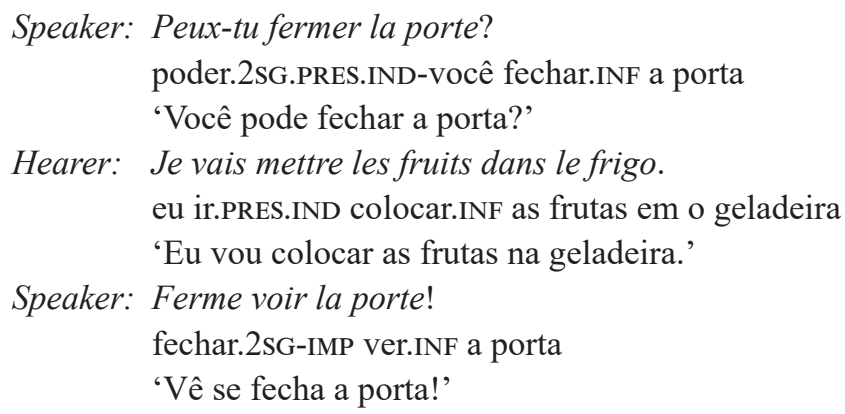

Esse exemplo também seria perfeitamente aceitável se nenhum contexto linguístico estivesse disponível, desde que a informação a que o falante tivesse acesso fosse óbvia ou suficientemente tangível no contexto extralinguístico. Nesses casos, o antecedente não seria formalmente pronunciado; ele estaria implícito no contexto extralinguístico. Assim, Ferme voir la porte! 'Vê se fecha a porta!' poderia ser dito em situações em que fosse evidente que havia barulho demais, ou em que o falante gostaria de privacidade para confessar um segredo, ou em que o falante estivesse com frio, ou em que suas mãos estivessem ocupadas com alguma coisa, e por isso seria impossível que ele fechasse a porta sozinho. Crucialmente, os enunciados com voir, como no exemplo em (18), são apenas apropriados se o antecedente, seja ele linguístico ou extralinguístico, estiver óbvio para os participantes do contexto discursivo. Consequentemente, seria considerado bizarro proferir (18) caso nenhum antecedente linguístico estivesse disponível (se nenhum pedido prévio houvesse sido feito) ou caso, por exemplo, o enunciado fosse pronunciado por um pai ou uma mãe e fosse dirigido a uma criança 
que é bem-comportada, estudiosa, e que faz seus deveres no prazo. Nesses casos, o enunciado seria ou incoerente ou mal sucedido.

(18) Fais voir tes devoirs!

fazer.2sG-IMP ver.INF tuas lições

'Vê se faz tuas lições!'

Em suma, enquanto um enunciado como (19a), sem voir, é utilizado simplesmente para fazer um pedido, (19b), com voir, ressalta o fato de que o ouvinte deveria inferir do contexto linguístico ou extralinguístico que ele deve fechar a porta. Dessa forma, (19b), mas não (19a), salienta o fato de que as circunstâncias requerem que o ouvinte execute uma ação específica expressa pelo verbo imperativo.

(19) a. Ferme la porte!

fechar.2sG.IMP a porta

'Fecha a porta!'

b. Ferme voir la porte!

fechar.2sG.IMP ver.INF a porta

'Vê se fecha a porta!' (com a pressuposição: dadas as circunstâncias, o ouvinte deve realizar essa ação)

Nesses contextos, voir é similar a donc (literalmente então) em alguns de seus usos em outras variedades do francês (ver, por exemplo, DOSTIE, 2004; VINCENT, 1993; VLEMINGS, 2003).

\section{Vê no Português Brasileiro}

Nesta seção, discutiremos os dados ambíguos do PB exemplificados em (5), repetidos abaixo em (20) por conveniência.

(20) Vê se me escuta!

Como mencionado na introdução, essa construção pode ter a mesma leitura de ordem enfática das construções do FA discutidas na seção anterior. No entanto, ela também pode ter uma leitura em que o verbo de percepção significa 'verificar'. Para comparar o FA e o PB, nós precisamos primeiro diferenciar as duas leituras que construções em PB como (20) podem receber. Nesta seção, iremos nos focar em aspectos específicos dessas leituras e discutiremos suas propriedades principais.

A leitura de ordem de verificação em (20) poderia ser enunciada, por exemplo, em um contexto em que o falante dissesse "a ligação [do telefone] está muito ruim; vamos testar para ver se você me ouve." Por outro lado, com a leitura de ordem enfática, 
(20) poderia ser enunciada em um contexto em que o falante dissesse "você nunca me escuta, você nunca presta atenção no que eu falo, mas, no final das contas, eu sempre estou certo".

Assim, essas duas leituras podem ser descritas como leituras de injunção; no entanto, as sentenças não veiculam as mesmas ordens. Em (20), por exemplo, com o significado de 'verificar', a intenção do falante é fazer com que o ouvinte verifique se ele (falante) pode ser ouvido; a intenção não é fazer com que o ouvinte preste atenção ao que está sendo dito, ou seja, à ordem dada em relação ao contexto linguístico ou extralinguístico. Para a interpretação de 'verificar', a ordem a ser executada é veiculada pelo verbo de percepção (que, nesse caso, tem o significado de 'verificar' ou 'determinar'). Uma paráfrase dessa ordem poderia ser (21a). Uma possível resposta a (20) poderia ser (21b), com o verbo de percepção, mas não (21c), com o verbo escutar.

(21) a. Verifique se você pode ou não pode me escutar.

b. Não, vê você se me escuta.

c. \#Eu não! Me escuta você!

Já com o significado de ordem enfática, apesar de a forma ver em (20) corresponder à segunda pessoa singular do modo imperativo, ela não veicula uma ordem para que o ouvinte verifique ou determine alguma coisa; ela expressa uma ordem enfática para que a ação denotada pelo segundo verbo seja executada. Por exemplo, (22) é uma paráfrase desse significado de (20). Uma resposta possível a (20) é reproduzida em (22b), com o segundo verbo, mas (22c), com o verbo de percepção, é impossível.

(22) a. Me escuta / escute! ${ }^{9}$

b. Eu não! Me escuta você!

c. \#Eu não! Vê você!

A despeito do fato de (22a) ser uma paráfrase de (20) com a leitura de ordem enfática, há uma diferença pragmática entre essas construções. Enquanto a sentença em (22a) é utilizada para fazer um pedido, dar uma ordem ou simplesmente chamar a atenção do ouvinte para algo que o falante acredita ser importante, a sentença em (20), com a leitura de ordem enfática, enfatiza que o ouvinte deveria levar o contexto em consideração e executar a ação específica denotada pelo segundo verbo. Pode ser o caso de que um pedido específico já tenha sido feito antes, mas ignorado pelo ouvinte (ou não ouvido), ou pode ser o caso que a informação no contexto esteja saliente tanto para o falante quanto para o ouvinte. Por exemplo, se A disser a B "você nunca me escuta, você nunca presta atenção no que eu falo, mas, no final das contas, eu sempre estou certo," e então enunciar (20), o que A está implicitamente afirmando é que B deveria

9 Em PB, há apenas uma forma verdadeira do imperativo, a segunda pessoa do singular; essa forma verdadeira pode alternar-se com uma forma supletiva no subjuntivo. Diferentemente do português europeu ou do espanhol, tanto o imperativo verdadeiro em PB como o supletivo são compatíveis com a negação (SCHERRE et al., 2007). 
realmente ouvi-lo dessa vez, porque, se B não o fizer, como aconteceu em situações anteriores, B provavelmente incorrerá nos mesmos problemas que antes. Esse contexto poderia estar implícito e ser óbvio para ambos em uma situação conversacional. Nas próximas seções, veremos que diferenças entre a leitura de ordem enfática e a de verificação são correlatas a distinções morfossintáticas.

$\mathrm{Na}$ leitura de verificação, o verbo de percepção apresenta um paradigma morfológico completo, como ilustrado em (23), com formas finitas, e em (24), com formas não finitas. Na realidade, como mostrado nos exemplos, as formas do imperativo (23a), do presente (23b) e do pretérito perfeito (23c) são aceitáveis. O verbo de percepção também pode aparecer na forma infinitiva (24a), em uma estrutura de futuro perifrástico composta pelo verbo ir no presente do indicativo e o verbo ver no infinitivo; no gerúndio (24b), em uma estrutura de passado contínuo composta pelo verbo estar no pretérito imperfeito, seguido pelo verbo ver no gerúndio; e no particípio (24c), aparecendo em uma estrutura de passado perfeito composta pelo verbo ter no pretérito imperfeito e o verbo ver no particípio.

(23) Formas [+FInITAs]

a. Vê se vai chover hoje.

b. Eu vejo se vai chover hoje.

c. Ela viu se ia chover hoje.

(24) Formas [-FInITAS]

a. Eu vou ver se choveu.

b. Eu estava vendo se tinha chovido.

c. Eu tinha visto se ia chover.

$\mathrm{Na}$ leitura de ordem enfática, pelo contrário, o verbo de percepção tem uma forma fixa, vê. Como ilustrado em (25) e (26), ele não pode assumir nenhuma outra forma, seja ela finita ou não finita. Nessa interpretação, ver apresenta então um paradigma defectivo que admite uma única forma, vê, no imperativo, na segunda pessoa, singular, como em (27). ${ }^{10}$

(25) Formas [+FInITAs]

a. "Eu vejo se (você) comeu!

b. "Você viu se (você) vai comer!

c. "Ela via se (você) estava comendo!

10 A forma supletiva do imperativo em (i) é aceita por alguns falantes.

(i) \%Veja se (você) come. 
(26) Formas [-FINITAs]

a. "Você está vendo se (você) vai comer!

b. "Você tinha visto se (você) comeu!

c. "Vai ver se (você) come!

(27) Vê se (você) come!

Quando ver recebe a leitura de verificação, trata-se de um verbo bivalente: dois argumentos são selecionados por esse predicado, um agente e um tema, como mostrado em (28); o agente é realizado por pro em (28a) e pelo pronome ela em (28b), e o tema é realizado pela oração em (28a, b) e pelo sintagma nominal em (28c). Os exemplos em (28d, e) mostram que esses dois argumentos são necessários. Também é possível inserir um PP benefactivo (31).

(28) a. pro vê [se tem gente aí fora]!

b. Ela viu [se tinha gente aí fora].

c. Vê o horário do trem.

d. * pro $_{\text {EXPL }}$ vê [se tem gente aí fora].

e. *pro vê.

(29) Vê [pra mim] se eu estou com febre!

Por outro lado, na leitura de ordem enfática, vê é uma forma fixa (no imperativo, segunda pessoa singular) que pode se combinar apenas com um constituinte: a oração introduzida por se em (30). O exemplo em (31) mostra que é impossível inserir um PP benefactivo.

(30) a. Vê [se fica quieto]!

b. ${ }^{\#} \mathrm{O}$ menino viu [se ficava quieto].

c. *pro ${ }_{\text {expl }}$ vê [se fica quieto]!

d. *pro vê.

(31) *Vê [pra mim] se fica quieto!

\section{Francês Acadiano vs. Português Brasileiro}

As duas seções anteriores descreveram as construções do FA e do PB que são utilizadas para veicular ordens enfáticas ${ }^{11}$. Como descrito em detalhes nas seções "Voir no Francês Acadiano" e "Vê no Português Brasileiro", essas formas não possuem as

11 Deixaremos de lado nesta seção o outro significado da construção do PB. 
propriedades morfossintáticas e semânticas dos verbos de percepção dos quais elas parecem ter derivado. Em contraste com os verbos lexicais voir (FA) e ver (PB), as formas voir e vê não se comportam como verbos plenos por serem formas fixas e invariáveis: em FA, voir aparece apenas no infinitivo, enquanto em PB apenas a forma na segunda pessoa do singular do imperativo é possível ${ }^{12}$. Além disso, essas formas, tanto em FA quanto em PB, não selecionam argumentos.

As propriedades sintáticas dessas formas, no entanto, não são as mesmas. Nas construções em FA, temos uma sentença imperativa em que voir parece exibir características similares às de clíticos, como ter que acompanhar o verbo imperativo, exceto caso coocorra com pronomes clíticos. Em $\mathrm{PB}$, a sentença fica no modo indicativo; a forma vê não se comporta como um pronome clítico, diferentemente de FA, já que não está presa a um verbo lexical; ao invés disso, a forma parece selecionar um complemento que aparece sob a forma de uma oração introduzida pelo complementizador se.

Apesar dessas diferenças sintáticas, as formas em FA e PB têm a mesma função pragmática: elas enfatizam uma ordem, sinalizando ao ouvinte que ele deve levar o contexto (linguístico ou extralinguístico) em consideração e executar a ação denotada pelo verbo lexical. Em outras palavras, essas construções somente podem ser enunciadas se alguma informação contextual for óbvia tanto para o falante quanto para o ouvinte ${ }^{13}$.

Como iremos discutir em mais detalhes na seção "Análise", analisaremos a forma voir do FA e a forma vê do PB como marcadores pragmáticos e proporemos uma análise sintática similar para ambas as construções, que é baseada no quadro teórico de Speas e Tenny $(2003)$ e Hill $(2007,2014)$. A próxima seção apresentará mais informações sobre esses trabalhos.

\section{Quadro teórico}

Diversos estudos na esteira do projeto cartográfico (RIZZI, 1997, 2013; CINQUE 1999; CINQUE; RIZZI, 2012; RIZZI; CINQUE, 2016) argumentam que os papéis pragmáticos de falante e ouvinte sejam codificados sintaticamente na periferia esquerda das sentenças (SPEAS; TENNY, 2003; HILL, 2007, 2014; HAEGEMAN, 2014; MIYAGAWA, 2012). Suas propostas visam explicar fenômenos como vocativos, concordância alocutiva, logoforicidade, partículas orientadas para o falante, advérbios gramaticalizados, entre outros.

De acordo com Speas e Tenny (2003) e Hill (2007, 2014), a pragmática conversacional está codificada na sintaxe por meio do sintagma Speech Act (SAP), uma estrutura predicativa performativa acima do domínio de CP. Essa proposta recupera a Hipótese Performativa de Ross (1970), de acordo com a qual mesmo sentenças

\footnotetext{
12 Vide nota 9.

13 Vide a discussão sobre o exemplo (16) e informação contextual.
} 
declarativas seriam performativas. Segundo Ross, em Estrutura Profunda (input da interpretação), uma sentença declarativa estaria encaixada em outra sentença contendo um verbo performativo que codificaria a força ilocucionária declarativa do enunciado. A estrutura de superfície seria derivada depois de a regra de apagamento do performativo ser aplicada para elidir a sentença subordinante.

A estrutura SAP proposta por Speas e Tenny, por outro lado, não envolve um verbo performativo; ela consiste de duas camadas que estendem a projeção funcional da sentença, como ilustrado em (32). Speas e Tenny, seguindo as ideias de Hale e Keyser (1999), argumentam que a estrutura SA obedece às mesmas restrições encontradas em estruturas argumentais. Assim, replicando a estrutura $v \mathrm{P}$ para a saturação de papéis temáticos, o núcleo de SA projeta uma estrutura que garantiria a saturação dos papéis pragmáticos, com duas posições de núcleo, dois especificadores e um complemento.

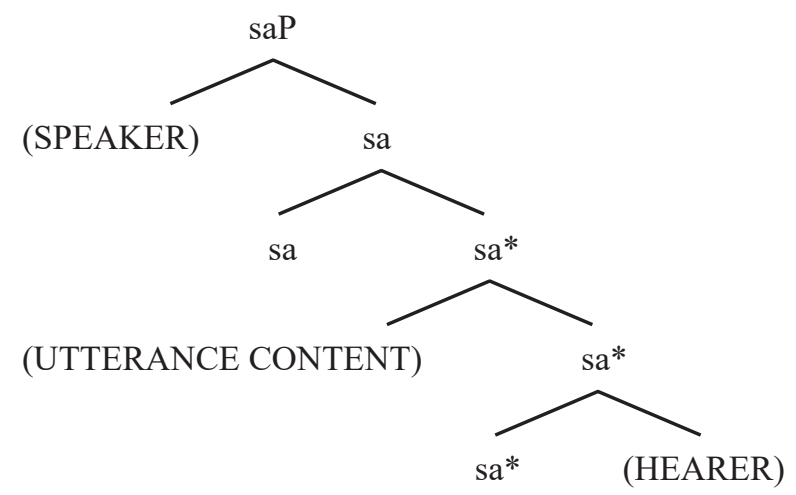

As autoras argumentam que o que está representado não são os atos de fala em si, mas as relações assimétricas entre os papéis pragmáticos de falante, interlocutor, e conteúdo do enunciado. Essa configuração estrutural explicaria as restrições observadas no número de atos de fala gramaticizados nas línguas em geral.

Com base em dados do romeno, Hill (2014, p. 147) propõe a representação modificada de (32), ilustrada em (33). 


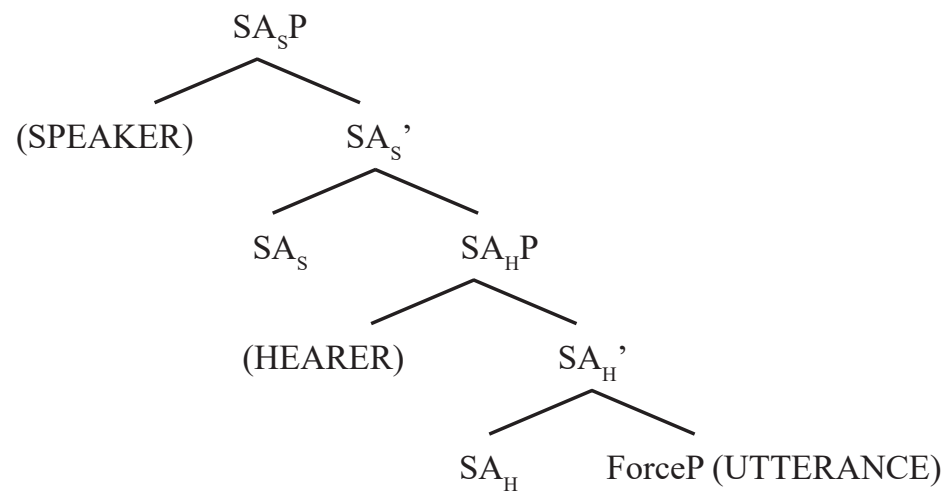

Hill argumenta que as partículas que denotam atos de fala em romeno forneceriam evidência lexical acerca do núcleo de ato de fala $(s a)$. Essas partículas pragmáticas acarretam uma interpretação predicativa, o que levaria à previsão de que seu comportamento sintático se segue de sua inserção na estrutura em algum dos níveis de SAP.

Contudo, de acordo com Hill, os dados do romeno sugerem que essas partículas não selecionam ouvintes, e sim CPs (entendidos como o conteúdo do enunciado) nucleados por complementizadores lexicais. Assim, não seria possível propor saP como substituto de ForceP, uma vez que Force, ao ser ocupado por um complementizador, não poderia alojar a partícula núcleo de speech act. Na representação de Hill, ForceP, associado ao papel de enunciado, é o complemento de $s a$, enquanto o papel pragmático de interlocutor é saturado em Spec de $s a P$, da mesma forma que objetos indiretos o são no $v$ P. Nas palavras de Hill (2014, p. 147):

[...] there is a speech act head SAh that behaves as a verb insofar as it merges with a direct complement (ForceP) and projects a phrase structure that allows for the merging of a constituent in the hearer position (Spec, $S A h P)$; the derivation extends with the speaker field (SAsP), where the speaker p-role is checked, possibly by a constituent merged in Spec, SAsP.

\section{Análise}

Como vimos, a construção do FA em (4) e a do PB em (5) podem ter a mesma leitura de ordem enfática. Nessa leitura, voir em FA e vê em PB compartilham algumas propriedades importantes, como a invariabilidade morfológica e a ausência de estrutura argumental; além disso, elas apresentam a mesma função pragmática (ver a seção "Francês Acadiano vs. Português Brasileiro"). Essas propriedades mostram que esses elementos passaram por um processo de descategorização e dessemantização e adquiriram função pragmática, o que é típico de um processo de pragmaticalização. 
Assim como Dostie (2004, 2009), nós entendemos que a pragmaticalização é um processo similar à gramaticalização, mas com um resultado que carrega uma função pragmática ao invés de uma mais gramatical. Dessa forma, as formas em FA e em PB não funcionariam como verbos lexicais encabeçando uma sentença matriz, mas sim como marcadores pragmáticos, enfatizando uma ordem ou um pedido. Como já discutimos, podemos dar conta das diferenças entre as construções do FA em (34) e do PB em (35) em termos pragmáticos. Enquanto, nos exemplos abaixo, os enunciados em (a) são ordens ou pedidos simples, os enunciados em (b) salientam o fato de que o ouvinte deveria se basear no contexto, que forneceria informação que garantiria que a ordem deveria ser executada.

(34) a. Ferme la porte!

b. Ferme voir la porte!

(35) a. Fecha a porta!

b. Vê se fecha a porta!

Nossa hipótese é que as construções de ordem enfática em FA e em PB são mono-oracionais, em que voir e vê funcionam como marcadores discursivos inseridos diretamente em domínios mais altos: SAP (HILL, 2007, 2014). Abaixo, discutiremos as especificidades dessas estruturas.

Ainda, vimos que as construções do PB podem ter outra interpretação, que chamamos de leitura 'de verificação'. Nesse caso, vê possui algumas outras propriedades que indicam que se trata de um verbo lexical encabeçando a sentença matriz de uma estrutura biorracional: ele apresenta um paradigma morfológico completo, assim como

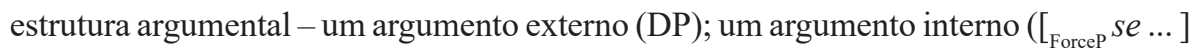
ou um DP) e um argumento opcional (um PP benefactivo). Nós apresentaremos uma análise detalhada dessa leitura abaixo.

Argumentamos que os marcadores de ato de fala voir em FA e vê em PB são inseridos diretamente em $\mathrm{SA}_{\mathrm{h}}$, o núcleo que codifica a relação pragmática do falante, para indicar o que este tem que fazer em vista do contexto (extra)linguístico (36). 
(36)
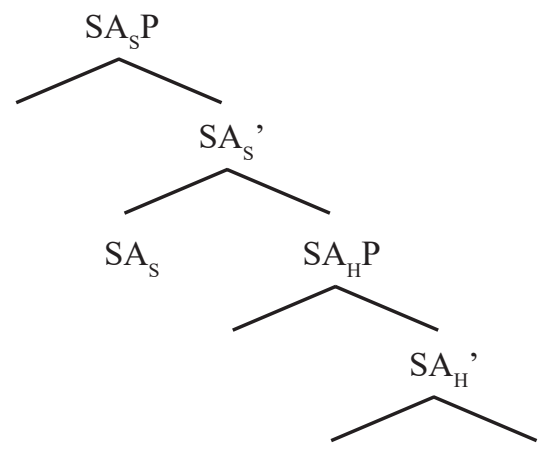

$$
\begin{aligned}
& \mathrm{SA}_{\mathrm{H}} \\
& \text { voir }
\end{aligned}
$$

A derivação da estrutura para sentença do FA em (37a) é dada em (37b-c).

(37) a. Ferme voir la porte!

fechar.2SG-IMP ver.INF a porta

'Vê se fecha a porta!'

b.

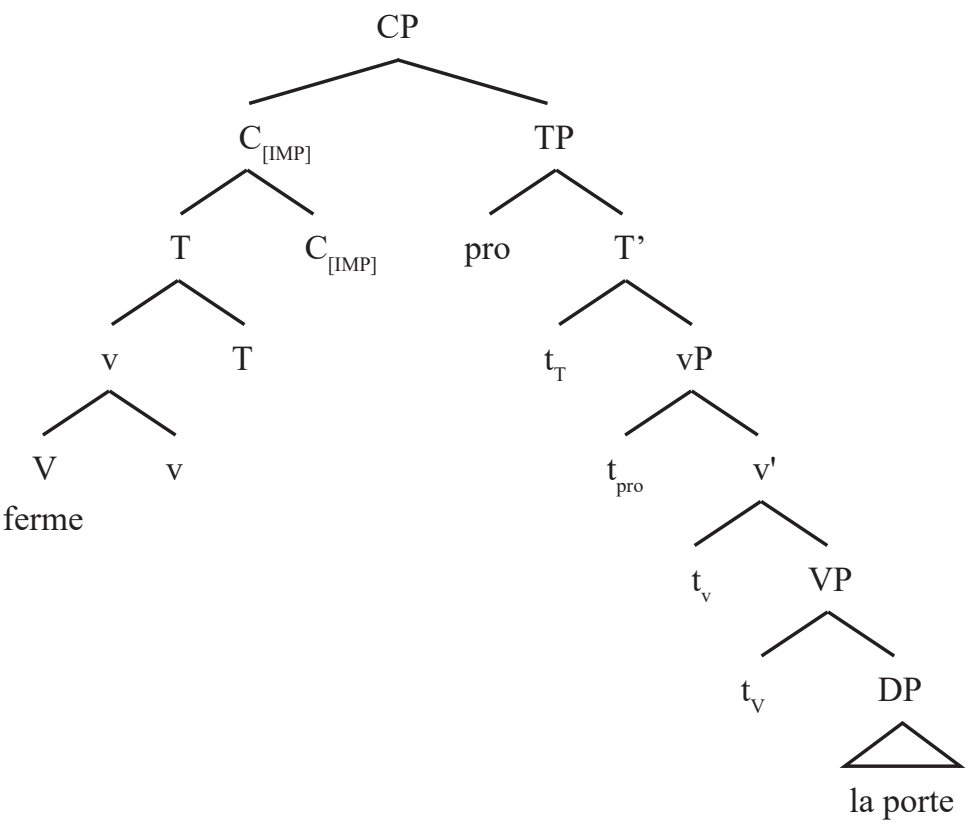


c.

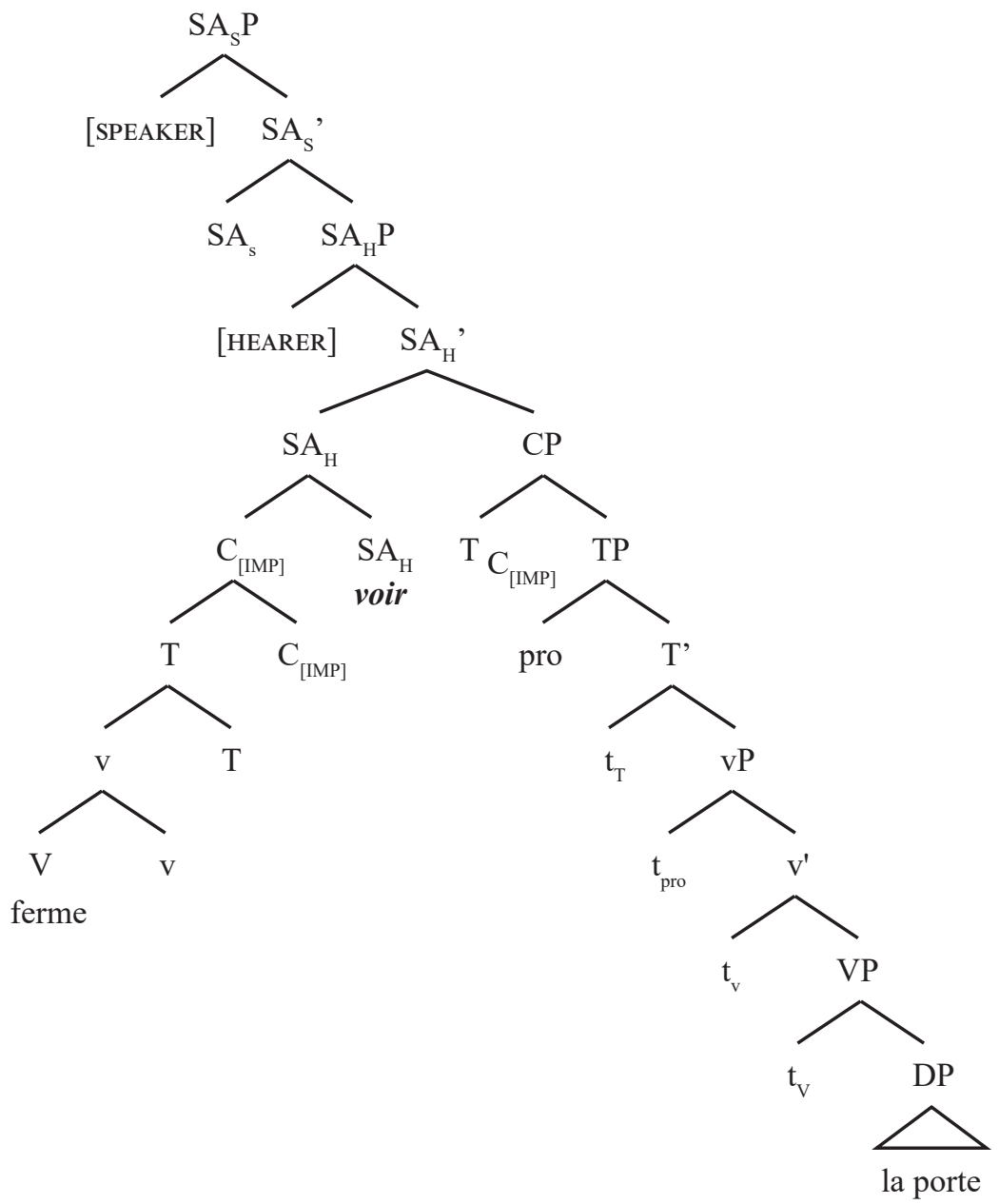

A derivação da estrutura para a sentença do PB em (38a) é dada em (38b-c). Argumentamos que o marcador pragmático vê nos enunciados do PB expressando ordem enfática é derivado do verbo lexical ver em seu uso tendo como complemento uma oração nucleada por se. Esse elemento funcional é inserido em $\mathrm{SA}_{\mathrm{H}}$ e seleciona um CP nucleado pelo complementizador se. $^{14}$

14 Sobre elementos funcionais que selecionam uma sentença, ver Cruschina (2015), Cruschina e Remberger (2018) e Hill (2014). 
(38) a. Vê se fecha essa porta!

b.

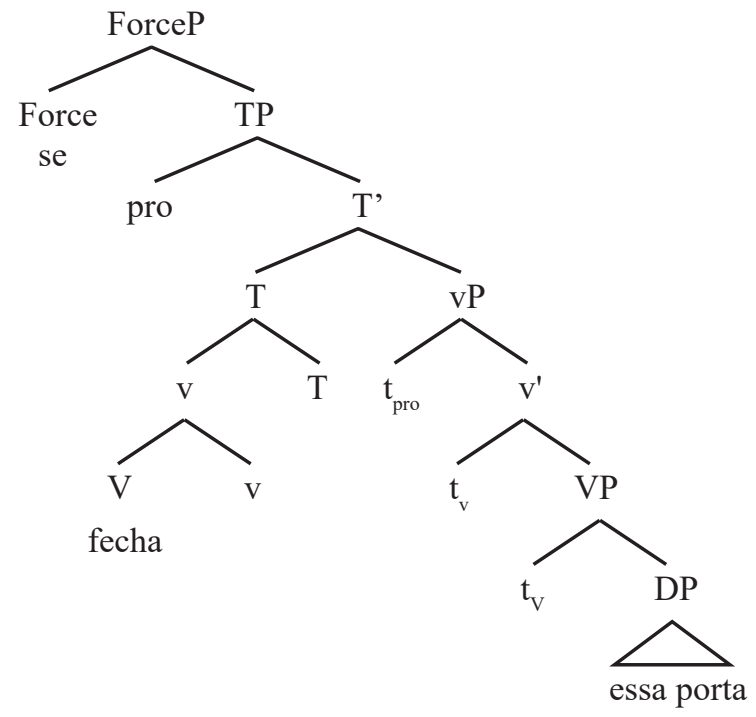

c.

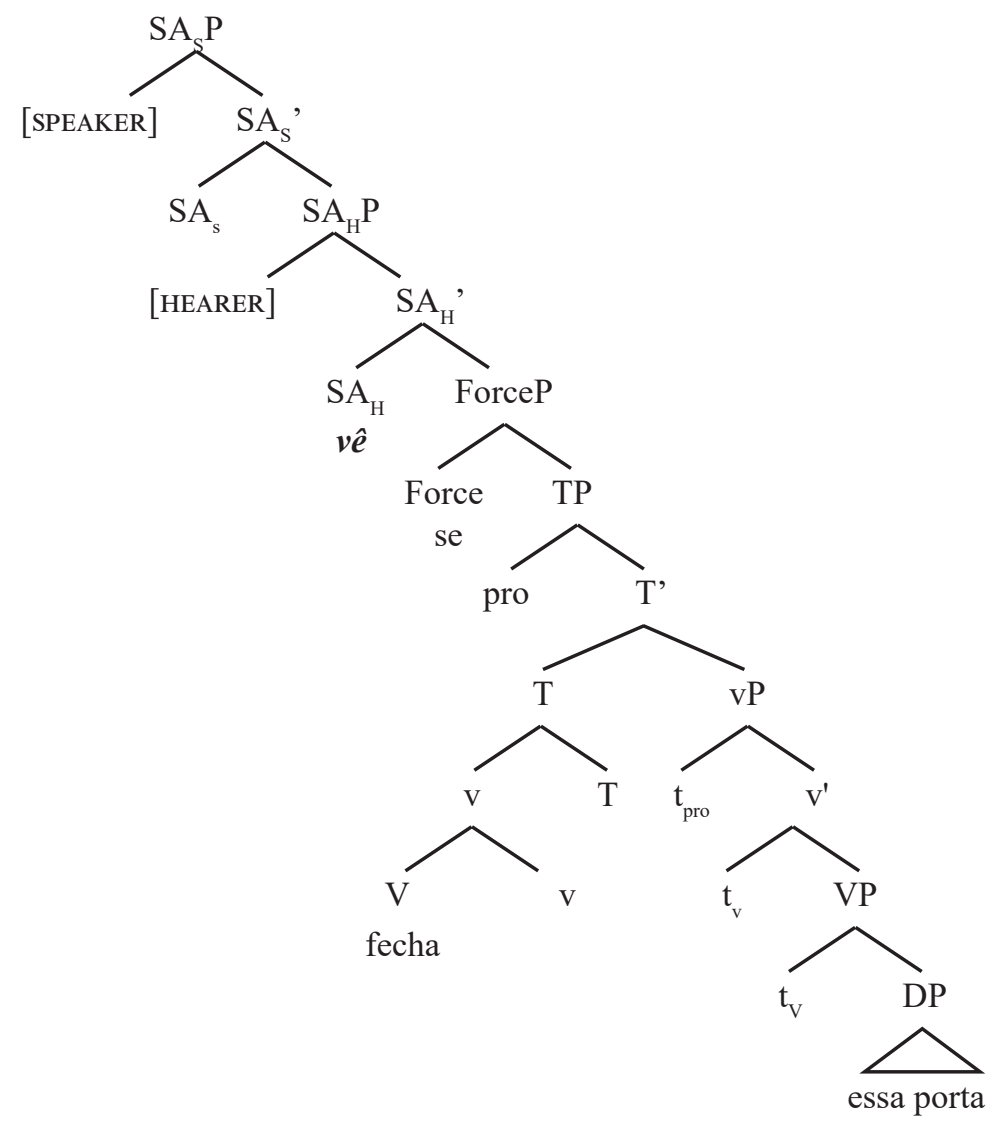


Essa análise prevê que vê não pode ser negado, uma vez que ocupa uma posição mais alta na representação sintática que aquela da negação. Essa previsão se confirma, como mostrado em (39) para o $\mathrm{PB}^{15}$.

(39) a. Vê se não reclama!

b. *Não vê se reclama!

Nossa hipótese para dar conta da leitura de verificação das sentenças do PB é que sejam estruturas biorracionais; nesse uso, vê é um verbo lexical, com a estrutura em (40).

(40)

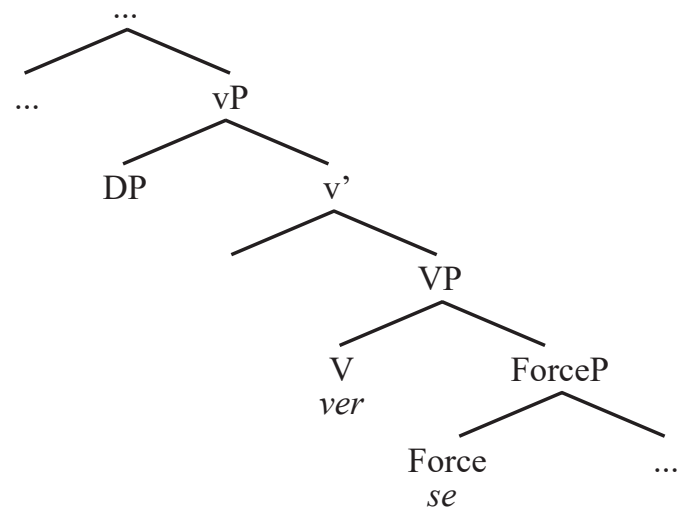

Essa estrutura prevê que haja dois domínios temporais na sentença e que ambos os verbos possam ser negados. Dados em (41) e (42) mostram respectivamente que essas previsões se confirmam.

(41) a. Eu vi se vai chover amanhã.

b. Estou vendo se choveu ontem.

(42) a. Vê se ela não precisa de ajuda!

b. Não vê se ele conserta carro!

c. Não vê se ele não tomou banho!

Esses dados mostram que a gama de significados geralmente associados a verbos de percepção, especialmente ao verbo "ver", deve ser ampliada. Somando-se aos significados de percepção direta, indireta e imaginativa, é possível incluir o significado de percepção de verificação (percepção com objetivo de verificação, inquirição, checagem). Argumentamos que esses dados corroboram a hipótese de Labelle (1996) e Boivin (1998) de que diferentes leituras de 'ver' estão associadas a uma única entrada lexical, que codifica um significado abstrato e subespecificado ('perceber'). Esse significado subespecificado se tornaria mais preciso de acordo com o complemento

$15 \quad$ Vide nota 9. 
do verbo de percepção. Dessa forma, o verbo 'ver' não é, em si próprio, ambíguo: suas múltiplas interpretações são o resultado de sua associação com tipos distintos de complementos. Essas estruturas diferentes instanciariam a seleção semântica de 'ver', que Labelle (1996) chama "Objeto de Percepção". Labelle argumenta que, dadas as múltiplas categorias semânticas que podem ser selecionadas por esse verbo (Proposição, Evento, Ação, Objeto), é preferível integrá-las em uma única categoria mais geral. Assim, todas as construções com um tipo semântico compatível com "Objeto de Percepção" poderiam ser complemento de 'ver'.

Nos casos discutidos neste artigo, o significado de verificação de 'ver' seria derivado do significado mais geral 'perceber'. Considerando que a definição de 'verificar' é "indagar ou examinar a veracidade de; averiguar, investigar" (Dicionário Houaiss, online), é possível argumentar que, para examinar a veracidade de uma situação, essa situação precisa primeiramente ser percebida. Portanto, em uma sentença como (43), o conteúdo expresso pela oração encabeçada por se pode ser verdadeiro ou falso, uma vez que o complementizador se introduz uma oração interrogativa cujo valor de verdade está em aberto (RODRIGUES; LUNGUINHO, 2017). É, portanto, essa "situação de valor de verdade em aberto" da oração com se que especifica o significado de 'ver' como 'verificação', 'averiguação'. ${ }^{16}$

(43) Vê se ela precisa de ajuda!

A Figura 1 resume a análise das construções estudadas.

Figura 1 - Análise

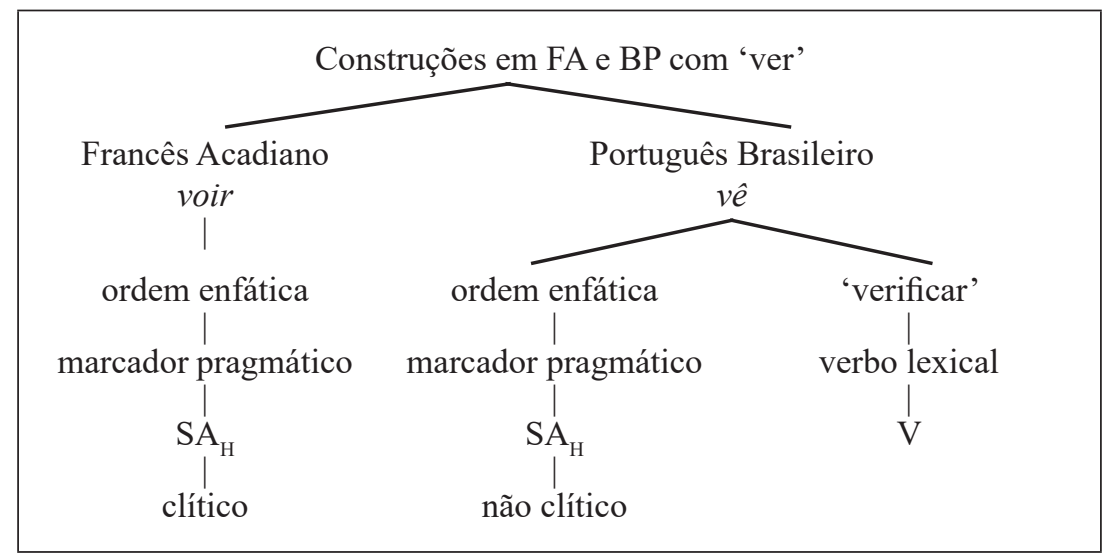

Fonte: Elaboração própria.

16 Em sentenças como (i), (ii) e (iii), cujos complementos são interrogativas indiretas, 'ver' também tem significado de verificação.

(i) Vê como a Maria pagou a conta da farmácia.

(ii) Vê por que a Maria ainda não chegou.

(iii) Vê quando a Maria vai chegar. 


\section{Considerações finais}

Neste artigo, descrevemos as propriedades de voir (francês acadiano) e vê (português brasileiro) utilizadas para veicular uma ordem enfática. Argumentamos que essas formas são elementos pragmaticalizados, isto é, marcadores pragmáticos injuntivos inseridos diretamente (externally merged) em SA ${ }_{\mathrm{H}}$ (HILL, 2007, 2014), e que as sentenças em que esses marcadores aparecem são realizações de diferentes operações aplicadas à mesma estrutura abstrata de núcleos (funcionais).

Nós também mostramos que vê em construções com a forma $[v \hat{e}+s e \ldots] \mathrm{em}$ português brasileiro pode estar associado a: a) uma leitura de ordem enfática, ou b) uma leitura de verificação. A despeito de serem superficialmente similares, essas duas opções são semântica e sintaticamente diferentes:

(i) quando vê expressa uma ordem enfática, [vê se...] é uma estrutura mono-oracional e vê é núcleo de $\mathrm{SA}_{\mathrm{H}}$;

(ii) quando vê expressa leitura de verificação, [vê se...] é uma estrutura bioracional e vê ú núcleo lexical.

LÉGER, C.; LUNGUINHO, M.; RODRIGUES, P. To see as a marker of contextual salience in romance languages evidence from Acadian French and Brazilian Portuguese. Alfa, São Paulo, v.65, 2021.

- ABSTRACT: This paper discusses constructions found in Brazilian Portuguese (BP) and Acadian French (AF), in which the equivalents of to see accompanies a second verb in imperative utterances. In these constructions in BP and AF to see emphasizes the command expressed by the other verb. The BP construction can also have an additional interpretation, in which vê 'see IMPERATIVE, 2,SINGULAR ' as the meaning 'to verify'. It is proposed that BP constructions can be associated to two different structures. The constructions with the 'to verify' meaning are treated as biclausal structures in which the verb ver 'to see'selects for a CP headed by the complementizer se 'if'. As for the analysis of the emphatic order meaning associated to the BP and AF constructions, we adopt the proposals put forth in Speas \& Tenny (2003) and Hill (2007, 2014) according to which conversational pragmatics is encoded in syntax as a predicative structure (Speech Act Projection - SAP) above CP. Following these ideas, we analyze BP and AF emphatic order constructions as monoclausal structures, where vê in $B P$ and voir in AF are injunctive pragmatic markers that are externally merged into the $S A$ head in order to encode a pragmatic relation.

- KEYWORDS: pragmatic marker; perception verbs; romance languages; grammaticalization; semantic bleaching. 


\section{REFERÊNCIAS}

AIKHENVALD, A. Y. Imperatives and commands. Oxford: Oxford University Press, 2010.

AKMAJIAN, A. The complement structure of perception verbs in an autonomous syntax framework. In: CULICOVER, P. W.; WASOW, T.; AKMAJIAN, A. (org.). Formal syntax. New York: Academic Press, 1977. p. 427-460.

BOIVIN, M. C. Complementation and interpretation: The concrete and imaginative readings of 'visual' perception verbs. MIT Working Papers in Linguistics, Cambridge, n. 25, p. 103-123, 1998.

BOUDREAU, É. Glossaire du vieux parler acadien: mots et expressions recueillis à Rivière-Bourgeois (Cap-Breton). Montreal: Éditions du Fleuve, 1988.

BRASSEUR, P. Dictionnaire des régionalismes du français de Terre-Neuve. Tübingen: Niemeyer, 2001.

CINQUE, G. Adverbs and functional heads: A cross-linguistic perspective. Oxford: Oxford University Press, 1999.

CINQUE, G.; RIZZI, L. The cartography of syntactic structures. In: HEINE, B.; NARROG, H. (org.). The Oxford Handbook of Linguistic Analysis. Oxford: Oxford University Press, 2012. p. 51-65.

CRUSCHINA, S. The expression of evidentiality and epistemicity: Cases of grammaticalization in Italian and Sicilian. Probus, Berlin, v. 27, n. 1, p. 1-31, 2015.

CRUSCHINA, S.; REMBERGER, E.-M. Speaker-oriented syntax and root clause complementizers. Linguistic Variation, Amsterdam, v. 18, n. 2, p. 336-358, 2018.

DAIGLE, J. O. A dictionary of the Cajun language. Ann Arbor (Michigan): Edwards Brothers Inc., 1984.

DOSTIE, G. Discourse markers and regional variation in French: A lexico-semantic approach. In: BEECHING, K.; ARMSTRONG, N.; GADET, F. (org.). Sociolinguistic variation in contemporary French. Amsterdam; Philadelphia: John Benjamins, 2009. p. 201-214.

DOSTIE, G. Pragmaticalisation et marqueurs discursifs: Analyse sémantique et traitement lexicographique. Brussels: De Boeck: Duculot, 2004.

FELSER, C. Verbal complement clauses. Amsterdam: John Benjamins, 1999.

FISCHER, K. (org.). Approaches to discourse particles. Oxford: Elsevier, 2006.

GUASTI, M. T. Causative and perception verbs: A comparative study. Torino: Rosenberg \& Sellier, 1993. 
HAEGEMAN, L. West flemish verb-based discourse markers and the articulation of the speech act layer. Studia Linguistica, Chichester, n. 68, p. 116-139, 2014.

HALE, K.; KEYSER, J. Bound features, merge and transitivity alternations. In: PYLKKÄNEN, L.; VAN HOUT, A.; HARLEY, H. (org.). Papers from the UPenn/ MIT Roundtable on the Lexicon. Cambridge: MIT Press, 1999. p. 49-72. (MIT Working Papers in Linguistics, 35).

HEINE, B.; NARROG, H. Grammaticalization and linguistics analysis. In: HEINE, B.; NARROG, H. (org.). The Oxford Handbook of Linguistic Analysis. Oxford: Oxford University Press, 2012. p. 401-423.

HENNEMANN, J.; NEUMANN-HOLZSCHUH, I. Les particules voir et - $t i$ dans le français acadien et louisianais : deux particules à cheval entre lexique et syntaxe. In: ARRIGHI, L.; LEBLANC, M. (org.). La francophonie en Acadie: Dynamiques sociales et langagières: Textes en hommage à Louise Péronnet. Sudbury: Prise de parole, 2014. p. 107-134.

HILL, V. Vocatives: How syntax meets with pragmatics. Leiden: Brill Publishers, 2014.

HILL, V. Vocatives and the pragmatics-syntax interface. Lingua, Amsterdam, n. 117, p. 2077-2105, 2007.

HOPPER, P. J.; TRAUGOTT, E. C. Grammaticalization. Cambridge: Cambridge University Press, 2003.

JARY, M.; KISSINE, M. When terminology matters: The imperative as a comparative concept. Linguistics, Berlin, v. 54, n. 1, p. 119-148, 2016.

KISSINE, M. From utterances to speech acts. Cambridge: Cambridge University Press, 2013.

LABELLE, M. Remarques sur les verbes de perception et la sous-catégorisation. Recherches linguistiques de Vincennes, Saint-Denis, n. 25, p. 83-106, 1996.

MILLER, P.; LOWREY, B. La complémentation des verbes de perception en français et en anglais. In: MILLER, P.; ZRIBI-HERTZ, A. (org.). Essais sur la grammaire comparée du français et de l'anglais. Paris: Presses Universitaires de Vincennes, 2003. p. 131-188.

MIYAGAWA, S. Agreements that occur mainly in the main clause. In: AELBRECHT, L.; HAEGEMAN, L.; NYE, R. (org.). Main clause phenomena: New Horizons. Amsterdam: John Benjamins, 2012. p. 79-112.

OLSSON, K. La construction: verbe + objet direct + complément prédicatif en français: Aspects syntaxiques et sémantiques. 1976. $\mathrm{PhD}$ Thèse (Docteur en Linguistique) - Université de Stockholm, Stockholm, 1976. 
PAPEN, R. A.; ROTTET, K. A structural sketch of the Cajun French spoken in Lafourche and Terrebonne parishes. In: VALDMAN, A. (org.). French and Creole in Louisiana. New York: Plenum, 1997. p. 71-108.

PARR, U. M. A glossary of the variants from standard French in Terrebonne Parish with an appendix of popular beliefs, superstitions, medicines, and cooking recipes. 1940. Dissertation (Master of Arts) - Louisiana State University, Baton Rouge, 1940.

POIRIER, P. Le glossaire acadien. Critical edition by Pierre M. Gérin. Moncton: Éditions d'Acadie: Centre d'études acadiennes, 1993.

RIZZI, L. Notes on cartography and further explanation. Probus, Berlin, n. 25, p. 197-226, 2013.

RIZZI, L. The fine structure of the left periphery. In: HAEGEMAN, L. (org.). Elements of grammar. Dordrecht: Kluwer, 1997. p. 281-337.

RIZZI, L.; CINQUE, G. Functional categories and syntactic theory. Annual Review of Linguistics, Palo Alto, v. 2, p. 139-163, 2016.

ROBERTS, I.; ROUSSOU, A. Syntactic change: A minimalist approach to grammaticalization. Cambridge (MA): Cambridge University Press, 2003.

RODRIGUES, P. Les compléments infinitifs et gérondifs des verbes de perception en portugais brésilien. 2006. PhD Thèse (Docteur en Linguistique) - Université du Québec à Montréal, Montreal, 2006.

RODRIGUES, P.; LUNGUINHO, M. V. Ver como marcador pragmático em português brasileiro. Revista Linguística, Rio de Janeiro, v. 13, n. 2, p. 231-262, 2017.

ROSS, J. R. On declarative sentences. In: JACOBS, R. A.; ROSENBAUM, P. S. (org.). Readings in English transformational grammar. Washington, DC: Georgetown University Press, 1970. p. 222-272.

SCHERRE, M. M. P.; CARDoso, D. B. B.; LUNGUINHO, M. V.; SALlE, H. Reflexões sobre o imperativo em português. Delta, São Paulo, v. 23, n. esp., p. 193241, 2007.

SEARLE, J. R. A taxonomy of illocutionary acts. In: GUNDERSON, K. (org.). Language, mind and knowledge. Minneapolis: University of Minnesota Press, 1975. p. 344-369.

SPEAS, M.; TENNY, C. Configurational properties of point of view roles. In: DI SCIULLO, A.M. (org.). Asymmetry in grammar. Amsterdam: John Benjamins, 2003. p. 315-344.

VALDMAN, A.; ROTTET, K. J.; ANCELET, B. J.; GUIDRY, R.; KLINGLER, T. A.; LAFLEUR, A.; LINDNER, T.; PICONE, M. D.; RYON, D. Dictionary of Louisiana 
French: As Spoken in Cajun, Creole, and American Indian Communities. Jackson: The University Press of Mississippi, 2010.

VINCENT, D. Les ponctuants de la langue et autres mots du discours. Quebec City: Nuit Blanche, 1993.

VLEMINGS, J. The discourse use of French donc in imperative sentences. Journal of Pragmatics, Amsterdam, n. 35, p. 1095-1112, 2003.

WIESMATH, R. Le français acadien: analyse syntaxique d'un corpus oral recueilli au Nouveau-Brunswick/Canada. Paris: L'Harmattan, 2006.

WILLEMS, D.; DEFRANCQ, B. L'attribut de l'objet et les verbes de perception. Langue française, Malakoff, n. 127, p. 6-20, 2000.

Recebido em 21 de maio de 2020

Aprovado em 22 de agosto de 2020 